\title{
BIO ANAL YTICAL METHOD FOR SIMULTANEOUS ESTIMATION OF EZETIMIBE AND PITAVASTATIN AND ITS APPLICATION TO PHARMACOKINETIC STUDIES USING UPLC
}

\author{
S. Prasanthi ${ }^{1}$, G. Himabindu ${ }^{* 1}$ \\ *, IDepartment of Engineering Chemistry, AUCE (A), Andhra University, Visakhapatnam- \\ 530003, India \\ ${ }^{1 *}$ Corresponding author: Email: himabinduauce@ gmail.com
}

Ph. No: 9550796566

\begin{abstract}
A simple, sensitive and rapid UPLC method was developed and validated for the simultaneous quantification of Ezetimibe and Pitavastatin. Separation was carried on $C_{18}$ column $(50 \times 2.1 \mathrm{~mm}$, 1.7 $\mu$ ) using a isocratic elution with a buffer containing $1 \mathrm{~mL}$ of Formic acid in 1Lit of water and the mixture of two components like Buffer and Acetonitrile in the ratio of 40:60 as mobile phase with $1 \mathrm{~mL} / \mathrm{min}$ flow rate at ambient temperature. Analysis was carried out within 10 minutes. The calibration curve was linear in the concentration range from $5.0 \mathrm{ng} / \mathrm{mL}$ to $100 \mathrm{ng} / \mathrm{mL}\left(r^{2}=0.999\right)$ for Ezetimibe and $2.0 \mathrm{ng} / \mathrm{mL}$ to $40 \mathrm{ng} / \mathrm{mL}\left(r^{2}=0.999\right)$ for Pitavastatin. All the parameters of system suitability, specificity, linearity and accuracy are in good agreement with USFDA guidelines and applied effectively for the investigation of pharmacokinetic studies in rabbit. Simple and efficient method was developed and utilized in pharmacokinetic studies to see the investigated analyte in body fluids.
\end{abstract}

Key words: UPLC, Ezetimibe, Pitavastatin, Validation, Rabbit plasma.

\section{Introduction}

Ezetimibe is a medication used to treat high blood cholesterol ${ }^{[1-2]}$ and certain other lipid abnormalities. Generally it is used together with dietary changes and a statin ${ }^{[3-4]}$. Alone, it is less preferred than a statin. It is taken by mouth. It is also available in the fixed combinations ezetimibe/simvastatin, ezetimibe/atorvastatin, and ezetimibe/rosuvastatin. The most commonly reported adverse events include upper respiratory tract infections ${ }^{[5-6]}$, joint pain, diarrhea ${ }^{[7]}$, and tiredness ${ }^{[8]}$. Serious side effects may include anaphylaxis ${ }^{[9-10]}$, liver problems, depression, and muscle breakdown ${ }^{[11]}$. Use in pregnancy and breastfeeding ${ }^{[12]}$ is of unclear safety. Ezetimibe works by decreasing cholesterol absorption in the intestines.

Pitavastatin (usually as a calcium salt) is a member of the blood cholesterol lowering medication class of statins ${ }^{[13]}$. Like other statins, it is an inhibitor of HMG-CoA 
reductase ${ }^{[14]}$, the enzyme that catalyses the first step of cholesterol synthesis ${ }^{[15]}$. Common statinrelated side effects (headaches, stomach upset, abnormal liver function tests and muscle cramps $^{[16]}$ ) were similar to other statins. However, pitavastatin seems to lead to fewer muscle side effects than certain statins that are lipid-soluble, as a result of the fact that pitavastatin is water-soluble (as is pravastatin, for example). One study found that coenzyme $\mathrm{Q}_{10}$ was not reduced as much as with certain other statins (though this is unlikely given the inherent chemistry of the HMG-CoA reductase pathway that all statin drugs inhibit) ${ }^{[17-18]}$. As opposed to other statins, there is evidence that pitavastatin improves insulin ${ }^{[19]}$ resistance in humans, with insulin resistance assessed by the homeostatic model assessment (HOMA-IR) method [20]. Hyperuricemia $^{[21]}$ or increased levels of serum uric acid ${ }^{[22]}$ have been reported with pitavastatin $^{[23]}$.

In drug discovery and production, bioanalysis is an integral component. Bioanalysis is related to the analysis of analytes in biological samples (drugs, metabolites, biomarkers) and requires several phases from sample collection to analysis of samples and reporting of results. The first phase is the selection of samples from clinical or preclinical trials, then sending the samples for analysis to the laboratory. Sample clean-up is the second step and it is a very critical step in bio-analysis. A robust and stable sample preparation system should be implemented in order to reach accurate results. The task of sample preparation is to remove interference from the matrix of the sample and improve the efficiency of the analytical method. Preparation of samples is often labor intensive and time consuming. The last step is the examination and detection of samples. The method of choice in bioanalytical laboratories is Ultra performance liquid chromatography (UPLC) for separation and detection. This is attributed to high selectivity and high sensitivity of the UPLC technique. In addition the information about the analyte chemical structure and chemical properties is important to be known before the start of bio-analytical work.

This work provides an overview of bioanalytical method development and validation. The main principles of method validation will be discussed. Commonly used sample preparation techniques will be presented. In addition the role of LC-MS/MS in modern bioanalysis will be discussed. In the present review we have our focus on bioanalysis of small molecules. Till date, no method is available for bio-analysis of ezetimibe and pitavastatin in any type of biological matrix. This is the first time to report a bio-analytical method for these drugs.

\section{Experimental Study}

\section{Chemicals}

Acetonitrile, formic acid and water (HPLC grade), were purchased from Merck Ltd. Worli, Mumbai, India. APIs of Ezetimibe and Pitavastatin as reference standards were procured from Spectrum Pharma research solutions pvt. Ltd, Hyderabad. 


\section{Instrumentation}

Agilent1290 Infinity II LC model of UPLC monitored with empower 2 data handling system and fitted with $\mathrm{C}_{18}$ column $(50 \times 2.1 \mathrm{~mm}, 1.7 \mu)$ and a detector of photo diode array was used for this study.

\section{Preparation of Buffer}

$1 \mathrm{ml}$ of formic acid is dissolved in 1lt of HPLC grade water and filter through $0.45 \mu$ filter paper.

\section{Preparation of Mobile phase}

Add buffer and acetonitrile in 40:60 ratios, mixed thoroughly, sonicated for $5 \mathrm{~min}$ and filtered through $0.45 \mu$ filter paper and used as mobile phase.

\section{Diluent}

Mobile phase was used as diluent.

\section{Chromatographic conditions}

Chromatographic separation, using $\mathrm{C}_{18}$ column (50 x $2.1 \mathrm{~mm}, 1.7$ micron), was administered in isocratic mode at room temperature. As a mobile phase, a mix of 0.1 percent formic acid and acetonitrile at $40: 60 \mathrm{v} / \mathrm{v}$ with a flow of $1.0 \mathrm{ml} / \mathrm{min}$ was used. $5 \mu \mathrm{l}$ was the injection rate and the run time was 10 minutes.

\section{Preparation of standard solution (Ezetimibe 50ng/ml and Pitavastatin 20ng/ml):}

\section{Preparation of Ezetimibe parent stock solution}

Accurately weigh and transfer 5mg of Ezetimibe working standard into $100 \mathrm{ml}$ volumetric flask and add app. $70 \mathrm{ml}$ of diluent, sonicate to dissolve it for 30min. and made up to the mark with diluent. Take $4 \mathrm{ml}$ of the above solution and transferred into $10 \mathrm{ml}$ volumetric flask and made up to the mark with diluent.

\section{Preparation of Pitavastatin parent stock solution}

Accurately weigh and transfer $5 \mathrm{mg}$ of Pitavastatin working standard into $100 \mathrm{ml}$ volumetric flask and add approximately $70 \mathrm{ml}$ of diluent, sonicate to dissolve it for $30 \mathrm{~min}$. and made up to the mark with diluent. Take $1.6 \mathrm{ml}$ of the above solution and transferred into $10 \mathrm{ml}$ volumetric flask and made up to the mark with diluent.

\section{Preparation of Ezetimibe and Pitavastatin stock solution}

Take $1 \mathrm{ml}$ of the Ezetimibe parent stock solution and $1 \mathrm{ml}$ of Pitavastatin parent stock solution into $100 \mathrm{ml}$ volumetric flask and made up to the mark with diluent.

\section{Preparation of Ezetimibe and Pitavastatin standard solution}

For standard preparation, $200 \mu 1$ of plasma sample, $300 \mu 1$ of acetonitrile and $500 \mu 1$ of internal standard, $500 \mu 1$ of diluents and $500 \mu \mathrm{l}$ of standard stock to precipitate all the proteins and mix in the vortex cyclo mixture. Centrifuge at $500 \mathrm{rpm}$ for $30 \mathrm{~min}$. Collect the supernatant solution in HPLC vial and inject into the chromatogram. 


\section{Preparation of sample solution (Ezetimibe 25ng/ml and Pitavastatin 10ng/ml)}

For sample preparation, $200 \mu \mathrm{l}$ of plasma sample, $300 \mu 1$ of acetonitrile and $500 \mu 1$ of internal standard, $500 \mu 1$ of diluents and $500 \mu 1$ of sample stock to precipitate all the proteins and mix in the vortex cyclo mixture. Centrifuge at $500 \mathrm{rpm}$ for $30 \mathrm{~min}$. Collect the supernatant solution in HPLC vial and inject into the chromatogram.

\section{Preparation of Lovastatin (IS) stock solution}

Accurately weigh and transfer $5 \mathrm{mg}$ of Lovastatin working standard into $100 \mathrm{ml}$ volumetric flask and add app $70 \mathrm{ml}$ of diluent, sonicate to dissolve it for 30min. and made up to the mark with diluent. Take $0.2 \mathrm{ml}$ of the above solution and transferred into $10 \mathrm{ml}$ volumetric flask and made up to the mark with diluent. Further transfer $0.8 \mathrm{ml}$ of the above solution into $10 \mathrm{ml}$ flask and made up to the mark with diluents.

\section{Pharmacokinetic Study}

\section{Animals' parameters}

In this study six healthy white rabbits (body weight app. 2500grams) were obtained from Bioneeds India pvt 1td, Bengaluru. The protocol of animal study was approved by institute of animal ethics committee (Reg.No:1074/PO/Re/S/05/CPCSEA).

\section{Bio analytical Method validation}

The method was validated in selective, sensitive, linearity, accuracy and precise, matrix condition, recovery study, re-injection reproducibility and stability.

\section{Selectivity}

By analyzing the six different rabbit's plasma samples and to check interference at the retention time selectivity was conducted.

\section{Matrix effect}

By comparing the height area ratio from the six various drug free plasma samples for Ezetimibe and Pitavastatin to get matrix effect. Experiments were performed at MQC levels in triplicate with six different plasma lots with the suitable precision of $\leq 15 \%$.

\section{Precision and accuracy}

It was determined by replicate analysis of internal control samples at a lower limit of quantification (LLOQ), low quality control (LQC), medium quality control (MQC), high quality control (HQC) levels. The half of CV should be less than $15 \%$ and accuracy should be within $15 \%$ except LLOQ where $20 \%$.

\section{Recovery}

The analysis of six samples reproduce at each internal control concentration is by extracting the Ezetimibe and Pitavastatin. By comparing the height areas of extracted standards to the height areas of un-extracted standards, recovery is evaluated. 


\section{Carry over}

Carry over deals with the analyte retained by the chromatographic system during the matrix with an analyte concentration ULOQC and above the diluting this sample with blank matrix.

\section{Dilution integrity}

By spiking the matrix with an analyte concentration above the ULOQC and diluting this sample with blank matrix, the dilution integrity should be explained.

\section{Stability}

By comparing the act of stock solution stability under the stability sample with the sample from the fresh stock sample preparation. Sample Stability studies in plasma were performed at the LQC and HQC concentration levels using six replicates at each level. Analyte was considered stable if the change is smaller amount than $15 \%$ as per US FDA guidelines. The perfectness of spiked rabbit plasma stored at room temperature was evaluated for twenty four hrs. The stability of spiked rabbit plasma stored at RT in auto sampler was evaluated for twenty four hrs. The auto sampler stability(LQC,MQC and HQC) was evaluated by comparing the extract plasma samples that were injected immediately, with the samples that were re-injected after storing with wet extract stability at room temperature after $12 \mathrm{~h}$ and $18 \mathrm{~h}$ at $2-8^{\circ} \mathrm{C}$. the reinjection reproducibility was evaluated by comparing the extracted plasma samples that were injected immediately, with the samples that were re injected after storing in the dry extract stability at room temperature after $12 \mathrm{~h}$ and $18 \mathrm{~h}$ at $-20^{\circ} \pm 3^{\circ} \mathrm{C}$. The freeze thaw stability was conducted by comparing the steadiness samples that had been frozen at $-31^{\circ} \mathrm{C}$ and thawed 3 times, with freshly spiked internal control samples. The short term stability was conducted 7 days at $7^{\circ} \mathrm{C}$. For long term stability evaluation the concentrations obtained after $24 \mathrm{~h}$ were compared with initial concentration.

\section{Pharmacokinetic Study}

Before experimentation all animals are starved overnight and had water ad-libitum. Topical anesthetic procedure was used. Pharmacokinetic evaluation was performed for Ezetimibe and Pitavastatin formulations. The samples were administered to each rabbit under fasting conditions. After oral administration of Ezetimibe and Pitavastatin, blood samples were collected from rabbit marginal ear vein using a 25-guage, 5/8 inch needle by clipping the marginal ear vein with a paper clip shown in figure 2 with volume of $0.5 \mathrm{ml}$ to $1.0 \mathrm{ml}$ at $0.25,0.5,1,1.5,2,4,6,8$, 10, 12, 14, 16, 18, 20, 22 and 24hrs. The blood was collected in Eppendorf containing 10\% EDTA solution. Blood was centrifuged at $5000 \mathrm{rpm}$ for $30 \mathrm{mins}$ at $2-8^{\circ} \mathrm{C}$ temperature. The clear supernatant plasma were collected $\&$ stored at $-30^{\circ} \mathrm{C}$ till its analysis. The plasma samples were treated for liquid-liquid phase extraction and analyzed for drug content with developed analytical method. After the study the animals were returned to animal house for rehabilitation.

The pharmacokinetic parameters for Ezetimibe and Pitavastatin oral administration were determined from plasma concentration data. Pharmacokinetic parameters like AUC, $\mathrm{C}_{\max }, \mathrm{T}_{\max }$ the time at which $\mathrm{C}_{\max }$ occurred, $\mathrm{K}_{\mathrm{el}}, \mathrm{t} 1 \frac{1}{2}, \mathrm{Ka}$ and MRT were calculated using the data. Data was measured by the trapezoidal rule method from time zero to infinity of concentration-time curve. $\mathrm{C}_{\max }$ and $\mathrm{T}_{\max }$ were obtained from the graph. All values are expressed in mean $\pm \mathrm{SD}$. 


\section{Results and Discussion}

To acquire the best chromatographic conditions, we used different buffers with acetonitrile as mobile phase in different ratios for isocratic and gradient mode was tested. The mobile phase composition was modified at each trial to enhance the resolution and also to achieve acceptable retention times. Finally, $0.1 \%$ formic acid and ACN in isocratic mode at 40:60 v/v ratios was selected as mobile phase because it gives a maximum response of the selected drugs. In the optimization method we used different stationary phases like $\mathrm{C}_{18}, \mathrm{C}_{8}$ and $\mathrm{CN}$-propyl was used. From the different trials we get good peak shapes of Ezetimibe and Pitavastatin by using $\mathrm{C}_{18}$ column of dimensions $50 \mathrm{~mm} \times 2.1 \mathrm{~mm}, 1.7 \mu$ connected to a PDA detector. Mobile phase flow rates were performed at $1 \mathrm{~mL} / \mathrm{min}$. By applying the above conditions, we get the retention times of the two drugs Ezeitmibe and Pitavastatin were $7.963 \mathrm{~min}$ and $6.838 \mathrm{~min}$ respectively. We get $0.40 \%$ Ezetimibe and $0.10 \%$ of Pitavastatin as \% CV of six replicate injections; from the \% CV results we conclude that the suggested strategy is very specific. The method under progress has been validated pursuant to USFDA guidelines.

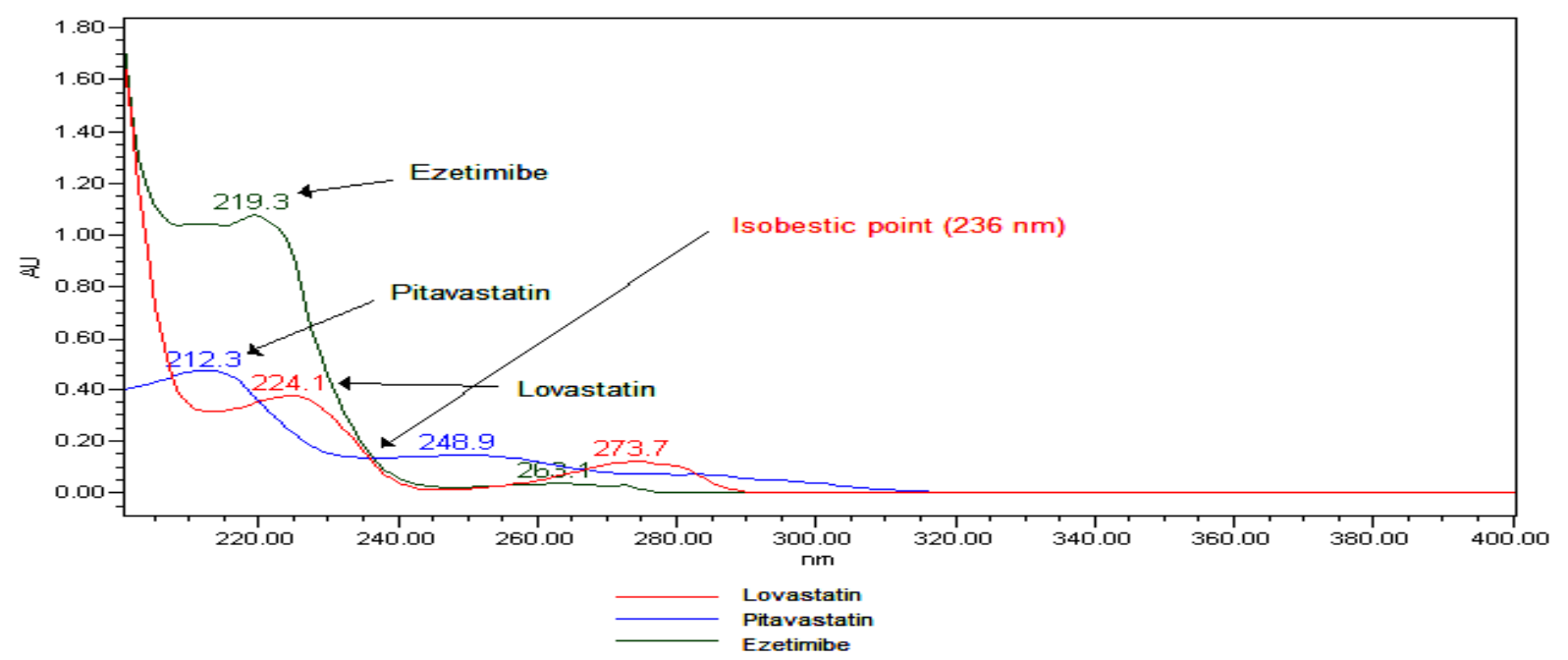

Figure 1. PDA spectra of Ezetimibe and Pitavastatin

Table 1. Optimized conditions of chromatography

\begin{tabular}{|c|c|}
\hline Parameter & Suitable condition \\
\hline Stationary Phase & $\mathrm{C}_{18}(50 \times 2.1 \mathrm{~mm}, 1.7 \mu)$ \\
\hline Mobile Phase & Acetonitrile $: 0.1 \%$ formic acid $(60: 40)$ \\
\hline Injection volume & $5 \mu 1$ \\
\hline Flow rate & $1.0 \mathrm{ml} / \mathrm{min}$ \\
\hline Column temperature & $25^{\circ} \mathrm{C}$ \\
\hline Wave length & $236 \mathrm{~nm}$ \\
\hline Run time & $10 \mathrm{~min}$. \\
\hline Retention time of Ezetimibe & $7.963 \mathrm{~min}$. \\
\hline Retention time of Pitavastatin & $6.838 \mathrm{~min}$. \\
\hline Retention time of Lovastatin (IS) & $2.946 \mathrm{~min}$. \\
\hline
\end{tabular}




\section{Specificity}

The specificity of the method to research Ezetimibe and Pitavastatin simultaneously is proved. The chromatograms of blank, standard and internal standard as shown in figure 2, 3 and 4 . The chromatograms of blank rabbit plasma and standard having no interference peaks were observed.

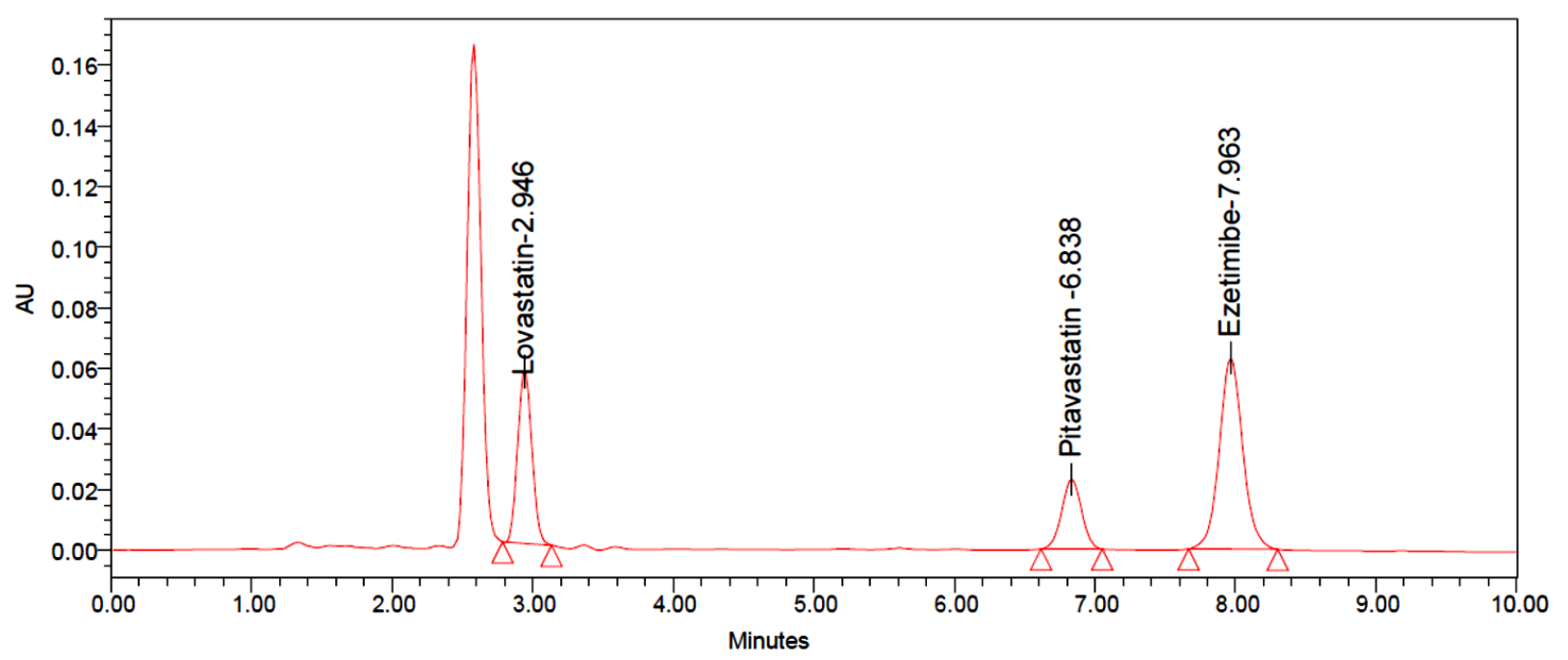

Figure 2. Chromatogram of Standard

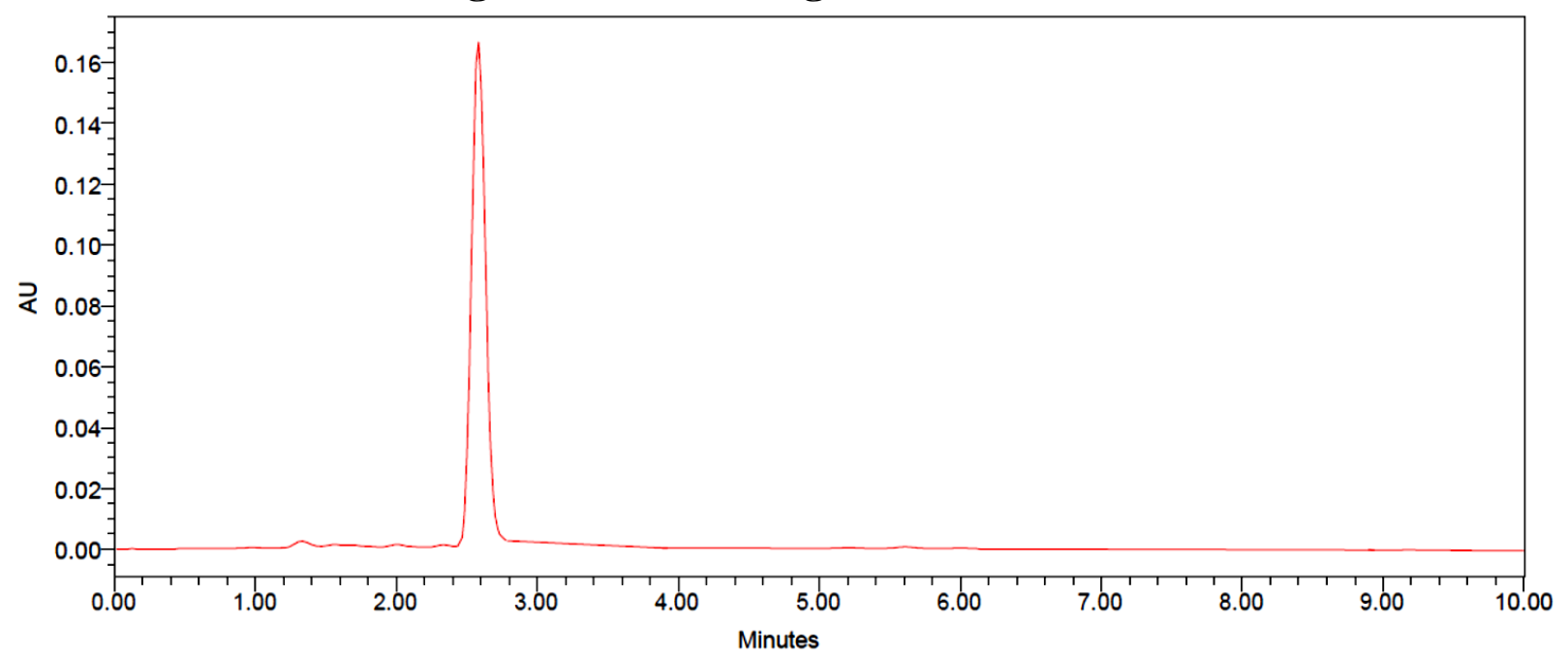

Figure 3. Chromatogram of blank 


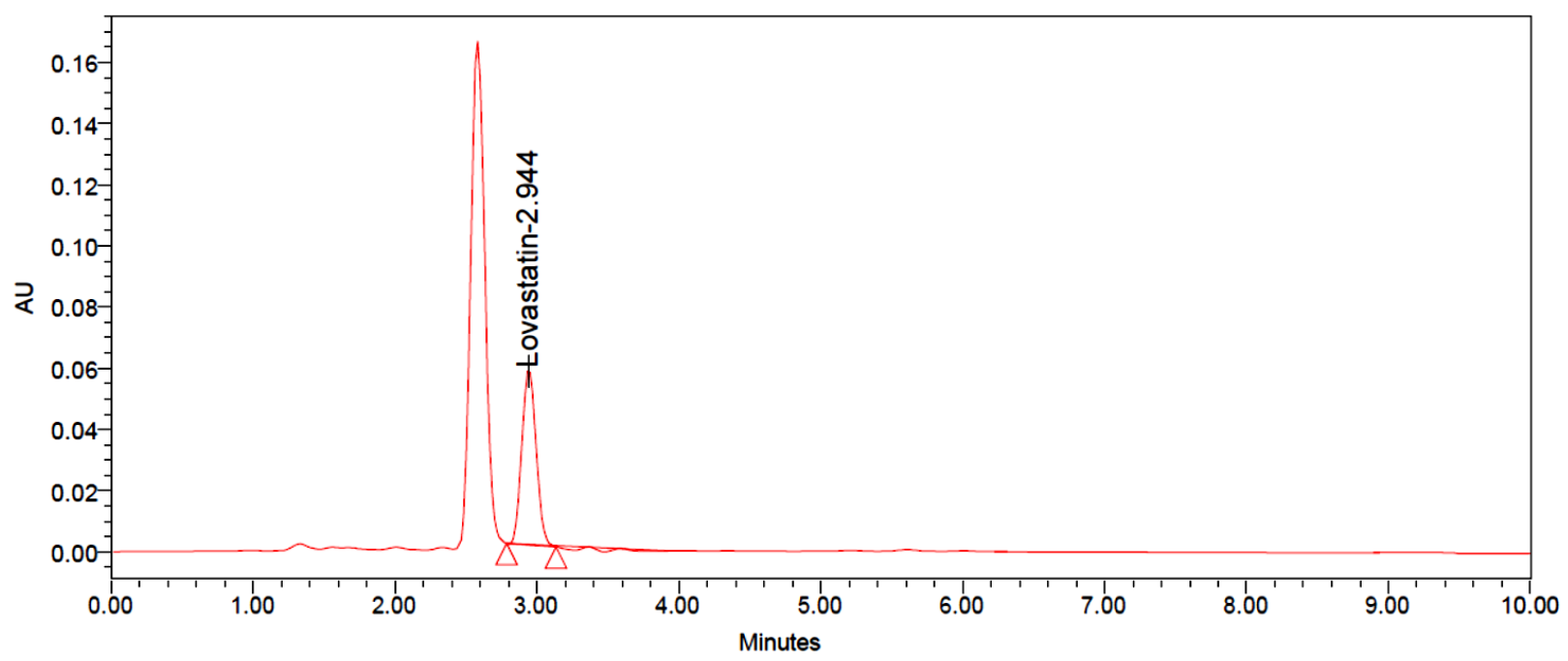

Figure 4. Chromatogram of blank plasma spiked with internal standard

\section{Matrix Effect}

The ion suppression/enhancement $\% \mathrm{CV}$ in the signal was found to be $1.0 \%$ at MQC level for Ezetimibe and Pitavastatin. It indicates that the matrix effect on the ionization of analyte is within the acceptable limit. In matrix effect LQC and HQC of Ezetimibe were 99.89 and 100.24 and Pitavastatin were 100.32, 100.15\%. \%CV of the both drugs at LQC level were 1.59, 1.78 and HQC level is $0.89,0.52$ respectively. It indicates that the matrix effect on the ionization of the analyte is within the suitable limit.

\section{Linearity}

From the calibration curve, it was clear that the peak area ratios were proportional to the concentration. The concentration range of Ezetimibe is $5.0-100 \mathrm{ng} / \mathrm{ml}$ and $2-40 \mathrm{ng} / \mathrm{ml}$ of Pitavastatin. The calibration curves were appeared linear and correlation coefficient was found to be 0.999 for Ezetimibe and Pitavastatin. Linearity results of Ezetimibe and Pitavastatin are shown in table 2.

Table 2. Linearity results of Ezetimibe and Pitavastatin

\begin{tabular}{|c|c|c|c|c|}
\hline \multirow[t]{2}{*}{ Linearity } & \multicolumn{2}{|c|}{ Ezetimibe } & \multicolumn{2}{|c|}{ Pitavastatin } \\
\hline & Conc. ng/ml & Peak response & Conc. ng/ml & Peak response \\
\hline 1 & 5.00 & 6259 & 2.00 & 1522.000 \\
\hline 2 & 12.50 & 16584 & 5.00 & 3925.000 \\
\hline 3 & 25.00 & 31287 & 10.00 & 7551.000 \\
\hline 4 & 37.50 & 47569 & 15.00 & 10765.000 \\
\hline 5 & 50.00 & 63254 & 20.00 & 14229.000 \\
\hline 6 & 62.50 & 79635 & 25.00 & 17564.000 \\
\hline 7 & 75.00 & 93521 & 30.00 & 21264.000 \\
\hline 8 & 100.00 & 122659 & 40.00 & 27947.000 \\
\hline Slope & \multicolumn{2}{|c|}{$\frac{1}{0.0231}$} & \multicolumn{2}{|c|}{0.0131} \\
\hline Intercept & \multicolumn{2}{|c|}{0.00087} & \multicolumn{2}{|c|}{0.00242} \\
\hline $\mathrm{CC}$ & \multicolumn{2}{|c|}{0.99967} & \multicolumn{2}{|c|}{0.99964} \\
\hline
\end{tabular}




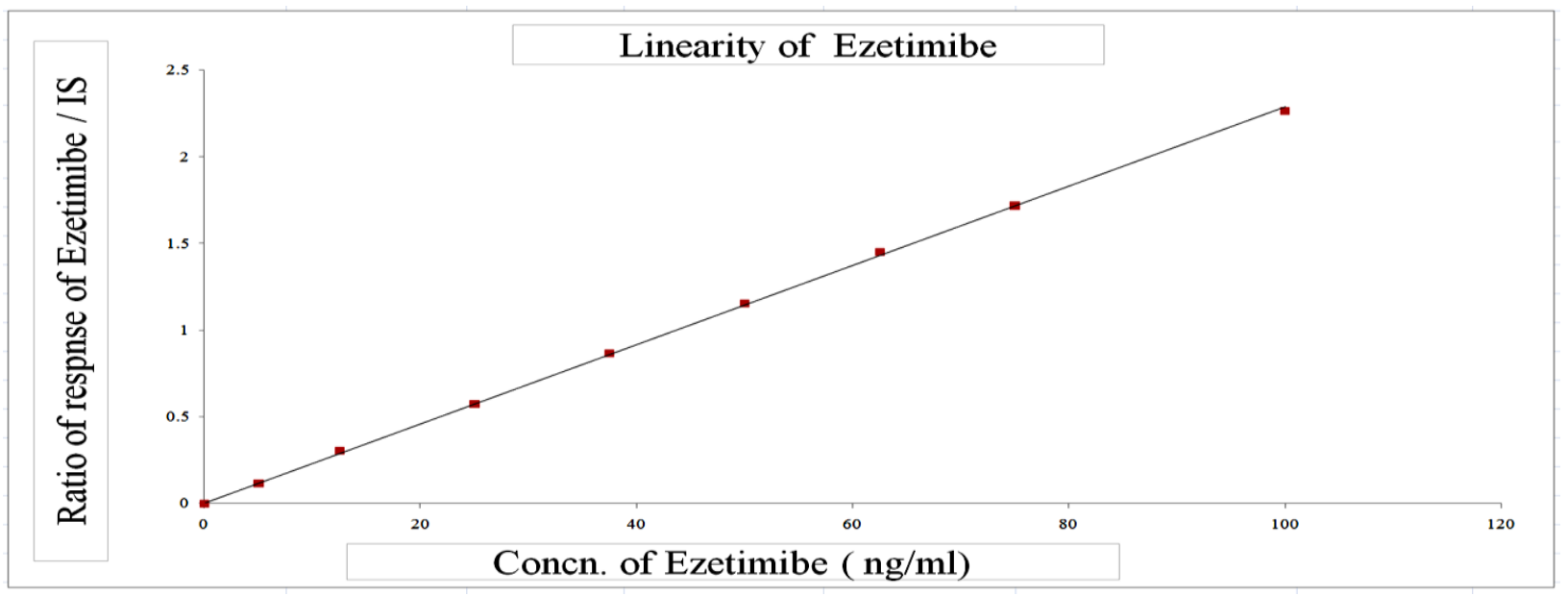

Figure 5. Calibration plot of Ezetimibe

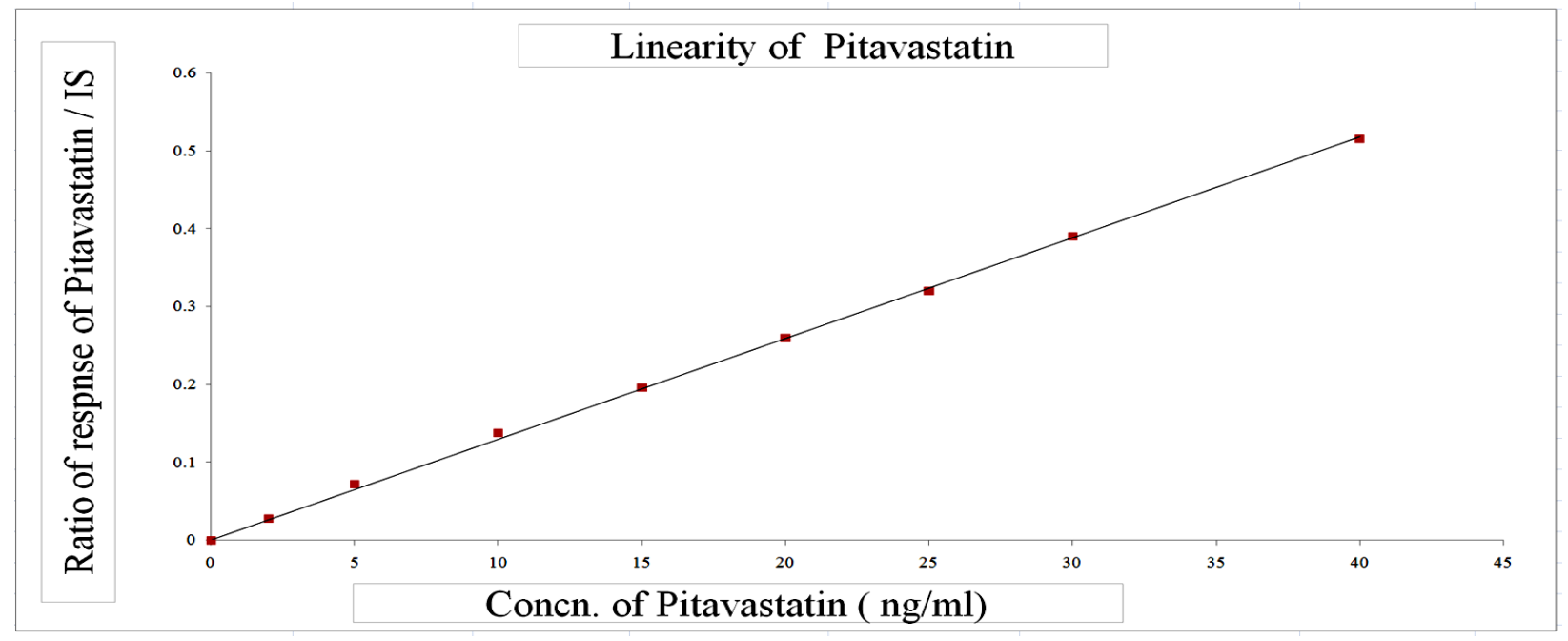

Figure 6. Calibration plot of Pitavastatin

\section{Precision and Accuracy}

The inter-run and accuracy were determined by pooling all individual assay results of replicate quality control over five separate batch runs analyzed on four different days. The $\% \mathrm{CV}$ of interrun precision was $<5 \%$ and the value of inter-run accuracy were in between 85 and 115 for Ezetimibe and Pitavastatin. From the data given in the following table 3, 4. It was clear that the method is precise and accurate.

Table 3. Precision and accuracy of Ezetimibe

\begin{tabular}{|c|c|c|c|c|}
\hline QC Name & LLQC & LQC & MQC & HQC \\
\hline Conc.(ng/ml) & $5 \mathrm{ng} / \mathrm{ml}$ & $25 \mathrm{ng} / \mathrm{ml}$ & $50 \mathrm{ng} / \mathrm{ml}$ & $75 \mathrm{ng} / \mathrm{ml}$ \\
\hline QC sample -1 & 6235 & 31142 & 63529 & 93456 \\
\hline QC sample -2 & 6198 & 31578 & 63124 & 93740 \\
\hline QC sample -3 & 6207 & 31659 & 63857 & 93851 \\
\hline QC sample -4 & 6224 & 31027 & 63765 & 93376 \\
\hline
\end{tabular}




\begin{tabular}{|c|c|c|c|c|}
\hline QC sample -5 & 6189 & 31246 & 63329 & 93451 \\
\hline QC sample -6 & 6199 & 31285 & 63058 & 93652 \\
\hline Mean & 6209 & 31323 & 63444 & 93588 \\
\hline SD & 17.466 & 247.253 & 330.289 & 188.417 \\
\hline \%CV & 0.28 & 0.79 & 0.52 & 0.20 \\
\hline Accuracy $(\%)$ & 97.37 & 98.24 & 99.49 & 97.84 \\
\hline
\end{tabular}

Table 4. Precision and accuracy of Pitavastatin

\begin{tabular}{|c|c|c|c|c|}
\hline QC Name & LLQC & LQC & MQC & HQC \\
\hline Conc.(ng/ml) & $2 \mathrm{ng} / \mathrm{ml}$ & $10 \mathrm{ng} / \mathrm{ml}$ & $20 \mathrm{ng} / \mathrm{ml}$ & $30 \mathrm{ng} / \mathrm{ml}$ \\
\hline QC sample -1 & 1574 & 7536 & 14775 & 21643 \\
\hline QC sample -2 & 1569 & 7531 & 14096 & 21098 \\
\hline QC sample -3 & 1493 & 7581 & 14052 & 21457 \\
\hline QC sample -4 & 1482 & 7493 & 14875 & 21536 \\
\hline QC sample -5 & 1528 & 7500 & 14653 & 21857 \\
\hline QC sample -6 & 1553 & 7569 & 14356 & 21265 \\
\hline Mean & 1533 & 7535 & 14468 & 21476 \\
\hline SD & 38.994 & 35.434 & 351.598 & 269.969 \\
\hline$\%$ CV & 2.54 & 0.47 & 2.43 & 1.26 \\
\hline Accuracy & 104.19 & 102.43 & 98.33 & 97.31 \\
\hline
\end{tabular}

\section{Recovery}

For recovery determination low, medium and high quality control concentration levels for Ezetimibe and Pitavastatin were prepared and the obtained areas for extracted samples of the same concentration levels from a precision and accuracy batch run on the same day. The mean recovery of Ezetimibe and Pitavastatin were $100.54 \%, 101.57 \%$ and $\% \mathrm{CV}$ were $1.74 \%, 2.56 \%$.

\section{Ruggedness}

The percent recoveries and percent $\mathrm{CV}$ of Ezetimibe and Pitavastatin determined with two different analysts and on two different columns were within acceptable criteria in HQC, LQC, MQC and LLQC samples. The results proved method is ruggedness. The percent recoveries ranged from $97.89-102.83 \%$ for Ezetimibe and $98.35 \%-103.88 \%$ for Pitavastatin. The results proved method is ruggedness.

\section{Auto sampler carryover}

Peak area response of Ezetimibe and Pitavastatin, wasn't observed within the blank rabbit plasma samples after successive injections of LLQC and ULQC at the retention times of Ezetimibe and Pitavastatin.

\section{Stability}

In solution stability analysis, Ezetimibe and Pitavastatin solutions were prepared with diluents and put in storage at $2-8^{\circ} \mathrm{C}$ in a refrigerator. Fresh stock solutions were related to age stock 
solutions prepared earlier $24 \mathrm{hrs}$. The stock solutions were stable up to $24 \mathrm{~h}$ when stored in 2$8^{\circ} \mathrm{C}$. Bench top and auto sampler stabilities were observed at LQC and HQC levels.

At room temperature Ezetimibe and Pitavastatin were stable in plasma for $24 \mathrm{~h}$, and $24 \mathrm{~h}$ in auto sampler at $20^{\circ} \mathrm{C}$. From this it was confirmed that, at LQC and HQC levels repeated freezing and thawing of plasma samples spiked with Ezetimibe and Pitavastatin did not affect their stability. From long-term stability it was clear that Ezetimibe and Pitavastatin were stable up to $24 \mathrm{~h}$ at a storage temperature of $-30^{\circ} \mathrm{C}$. The overall stability results of Ezetimibe and Pitavastatin were tabulated in table 5 and 6.

Table 5. Stability results of Ezetimibe

\begin{tabular}{|c|c|c|c|c|}
\hline \multicolumn{2}{|c|}{ Stability experiment spiked plasma } & \multirow{2}{*}{$\begin{array}{c}\begin{array}{c}\text { Spiked plasma Mean } \\
\text { conc. } \\
(\mathbf{n}=\mathbf{6}, \mathbf{n g} / \mathbf{m l})\end{array} \\
25.452\end{array}$} & \multirow{2}{*}{$\begin{array}{c}\begin{array}{c}\text { Std Dev } \\
(\mathbf{n}=6, \mathbf{n g} / \mathbf{m l})\end{array} \\
0.066\end{array}$} & \multirow{2}{*}{$\begin{array}{r}\% \mathrm{CV} \\
0.28\end{array}$} \\
\hline \multirow{3}{*}{ Bench top stability } & LQC & & & \\
\hline & MQC & 50.021 & 0.057 & 0.25 \\
\hline & HQC & 75.518 & 0.039 & 0.23 \\
\hline \multirow{3}{*}{$\begin{array}{l}\text { Auto sampler } \\
\text { stability }\end{array}$} & LQC & 25.509 & 0.095 & 0.54 \\
\hline & MQC & 50.114 & 0.038 & 0.45 \\
\hline & HQC & 75.523 & 0.074 & 0.52 \\
\hline \multirow{3}{*}{$\begin{array}{l}\text { Long term stability } \\
\text { (Day 28) }\end{array}$} & LQC & 25.537 & 0.066 & 0.75 \\
\hline & MQC & 50.312 & 0.037 & 0.34 \\
\hline & HQC & 75.541 & 0.043 & 0.16 \\
\hline \multirow{3}{*}{$\begin{array}{l}\text { Freeze thaw } \\
\text { stability }\end{array}$} & LQC & 25.532 & 0.025 & 0.58 \\
\hline & MQC & 50.129 & 0.064 & 0.3 \\
\hline & HQC & 75.498 & 0.072 & 0.29 \\
\hline \multirow{3}{*}{ Wet extract stability } & LQC & 25.496 & 0.038 & 0.48 \\
\hline & MQC & 50.958 & 0.049 & 0.29 \\
\hline & HQC & 75.481 & 0.073 & 0.31 \\
\hline \multirow{3}{*}{ Dry extract stability } & LQC & 25.501 & 0.059 & 0.75 \\
\hline & MQC & 50.009 & 0.061 & 0.33 \\
\hline & HQC & 75.518 & 0.027 & 0.25 \\
\hline \multirow{3}{*}{ Short term stability } & LQC & 25.529 & 0.038 & 0.34 \\
\hline & MQC & 50.463 & 0.060 & 0.26 \\
\hline & HQC & 75.518 & 0.057 & 0.07 \\
\hline
\end{tabular}

Table 6. Stability results of Pitavastatin

\begin{tabular}{|c|c|c|c|c|}
\hline \multicolumn{2}{|c|}{ Stability experiment spiked plasma } & \multirow{2}{*}{$\begin{array}{c}\begin{array}{c}\text { Spiked plasma } \\
\text { Mean conc. } \\
\text { (n=6, ng/ml) }\end{array} \\
10.021\end{array}$} & \multirow{2}{*}{$\begin{array}{c}\begin{array}{c}\text { Std Dev } \\
(\mathrm{n}=\mathbf{6}, \mathbf{n g} / \mathbf{m l})\end{array} \\
0.014\end{array}$} & \multirow{2}{*}{$\begin{array}{r}\% \mathrm{CV} \\
0.38\end{array}$} \\
\hline \multirow{3}{*}{ Bench top stability } & LQC & & & \\
\hline & MQC & 20.214 & 0.059 & 1.19 \\
\hline & HQC & 30.229 & 0.011 & 1.08 \\
\hline \multirow{3}{*}{$\begin{array}{c}\text { Auto sampler } \\
\text { stability }\end{array}$} & LQC & 10.127 & 0.075 & 0.79 \\
\hline & MQC & 20.174 & 0.038 & 0.88 \\
\hline & HQC & 30.368 & 0.074 & 1.02 \\
\hline Long term stability & LQC & 10.218 & 0.065 & 0.47 \\
\hline
\end{tabular}




\begin{tabular}{|c|c|c|c|c|}
\hline \multirow{4}{*}{$\begin{array}{c}\text { Freeze thaw } \\
\text { stability }\end{array}$} & MQC & 20.316 & 0.029 & 1.47 \\
\cline { 2 - 5 } & HQC & 30.004 & 0.014 & 0.55 \\
\cline { 2 - 5 } & LQC & 10.429 & 0.077 & 0.31 \\
\cline { 2 - 5 } & MQC & 20.316 & 0.032 & 0.61 \\
\hline \multirow{3}{*}{ Wet extract stability } & HQC & 30.279 & 0.065 & 1.18 \\
\cline { 2 - 5 } & LQC & 10.041 & 0.051 & 0.22 \\
\cline { 2 - 5 } & MQC & 20.462 & 0.047 & 0.79 \\
\hline \multirow{3}{*}{ Sry extract stability } & HQC & 30.318 & 0.043 & 0.16 \\
\cline { 2 - 5 } & LQC & 10.218 & 0.087 & 0.026 \\
\cline { 2 - 5 } & HQC & 20.164 & 0.022 & 0.78 \\
\cline { 2 - 5 } & LQC & 30.084 & 0.015 & 0.34 \\
\cline { 2 - 5 } & MQC & 10.032 & 0.048 & 1.18 \\
\hline
\end{tabular}

\section{Pharmacokinetic Study}

The method has been validated successfully to quantify the concentration of Ezetimibe and Pitavastatin in six different rabbits, after administration of Ezetimibe and Pitavastatin sample as an oral dose, under fasting condition. After injecting the drug samples into a rabbit body, collect the samples at different time intervals like $0.25,0.5,1,1.5,2,4,6,8,10,12,14,16,18,20,22$ and $24 \mathrm{hrs}$ from the rabbit body. After that as per test method sample is prepared and injected into the chromatographic system and record the values. The evaluated pharmacokinetic parameters were $\mathrm{C}_{\max }$ (maximum observed drug concentration-time measured 6hrs, using the trapezoidal rule), $\mathrm{t}_{\max }$ (time to observed maximum drug concentration), $\mathrm{K}_{\mathrm{el}}$ (apparent first order terminal rate constant calculated from a semi-log plot of the plasma concentration versus time curve, using the method of the least square regression) and $\mathrm{t}_{1 / 2}$ (terminal half-life as determined by the quotient 0.693/Kel $)$. The ratio of test/reference for $\mathrm{C}_{\mathrm{mx}}, \mathrm{AUC}_{0-12}$ and $\mathrm{AUC}$ were 89.24, 93.17 respectively and found to be within the acceptable limit of $80 \%-125 \%$. Table 7 shows the pharmacokinetic parameters of Ezetimibe and Pitavastatin.

Table 7. Mean pharmacokinetic parameters of Ezetimibe and Pitavastatin

\begin{tabular}{|c|c|c|}
\hline Pharmacokinetic parameters & Ezetimibe & Pitavastatin \\
\hline $\mathrm{AUC}_{0-\mathrm{t}}(\mathrm{ng} \mathrm{h} / \mathrm{ml})$ & $985 \mathrm{ng} \mathrm{h} / \mathrm{mL}$ & $248 \mathrm{ng} \mathrm{h} / \mathrm{mL}$ \\
\hline $\mathrm{C}_{\max }$ & $47 \mathrm{ng} / \mathrm{mL}$ & $19 \mathrm{ng} / \mathrm{mL}$ \\
\hline $\mathrm{AUC}_{0-\infty}(\mathrm{ng} \mathrm{h} / \mathrm{ml})$ & $985 \mathrm{ng} \mathrm{h} / \mathrm{mL}$ & $248 \mathrm{ng} \mathrm{h} / \mathrm{mL}$ \\
\hline $\mathrm{T}_{1 / 2}$ & $22 \mathrm{hrs}$ & $12 \mathrm{hrs}$ \\
\hline $\mathrm{T}_{\max }(\mathrm{h})$ & $4 \mathrm{hrs}$ & $1 \mathrm{hr}$ \\
\hline
\end{tabular}

$\mathrm{AUC}_{0-\infty}$ : Area under the curve extrapolated to infinity

$\mathrm{AUC}_{0-t}$ : Area under the curve up to the last sampling time

$\mathrm{C}_{\max }$ : The maximum plasma concentration

$\mathrm{T}_{\text {max }}$ : The time to reach peak concentration

$\mathrm{T}_{1 / 2}$ : Time the drug concentration 


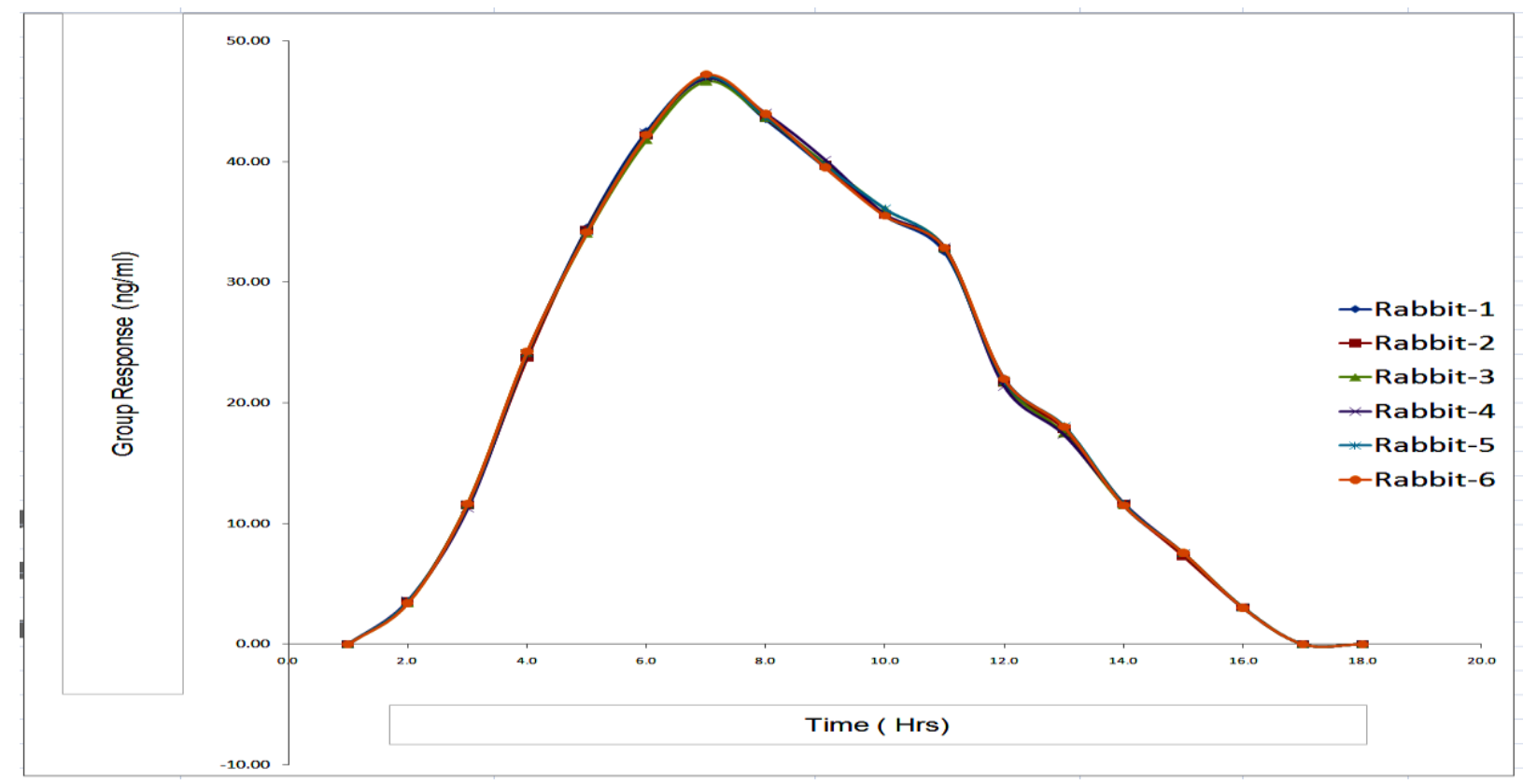

Figure 7. Recovery plot of Ezetimibe

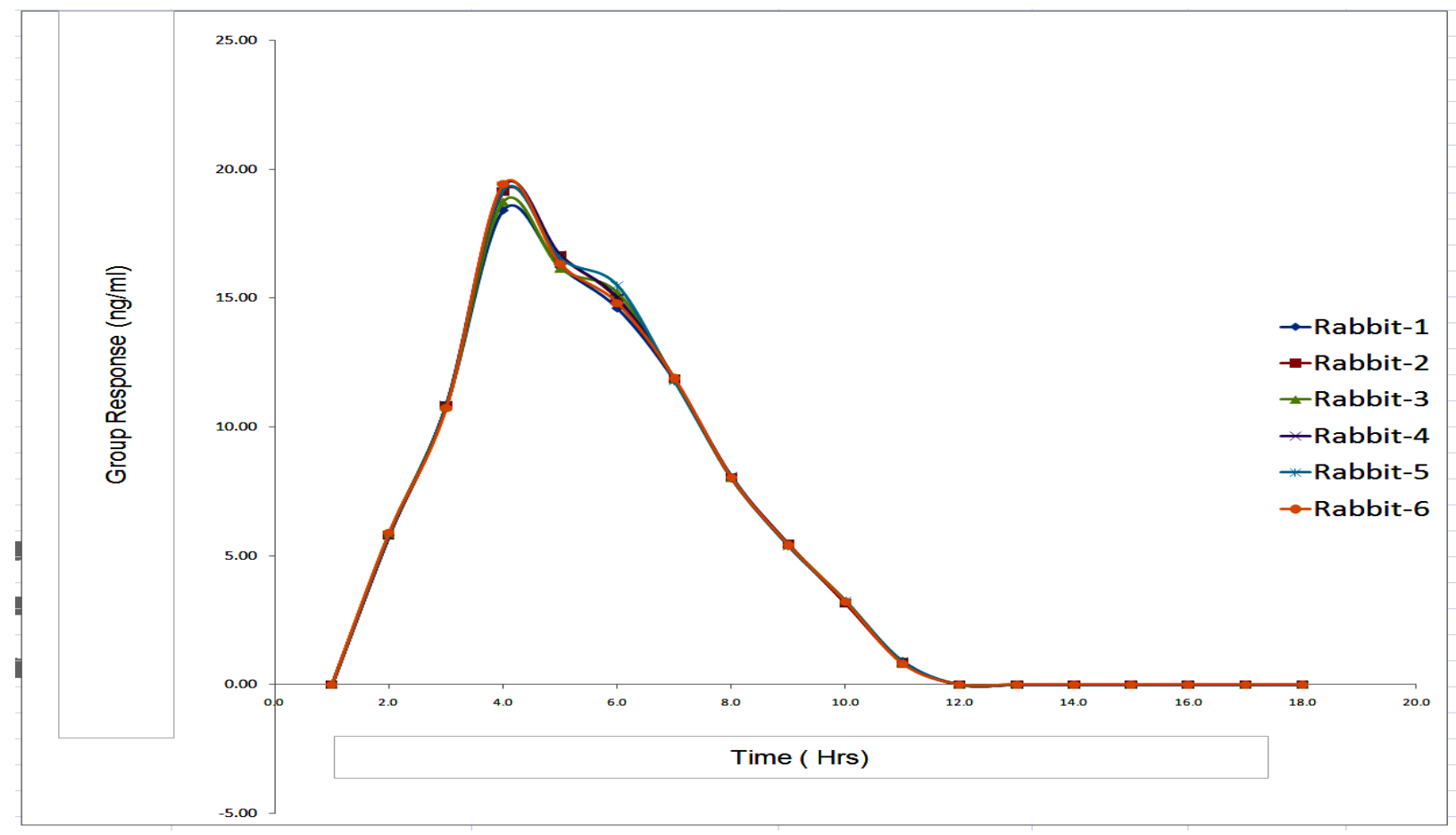

Figure 8. Recovery plot of Pitavastatin

\section{Conclusion}

For the first time higher sensitive UPLC method was developed and validated for the determination of Ezetimibe and Pitavastatin in rabbit plasma. Here the described method is fast, rugged, reproducible bio analytical method. Simple and efficient method was developed and can be used in pharmacokinetic studies and to check the investigated analyte in body fluids. 


\section{Acknowledgement}

I thankful to my guide for encouragement and supporting to finish this research work.

\section{Conflicts Of Interest}

Authors declare that there were no conflicts of interest.

\section{Funding Source}

None

\section{References}

[1] Bhatnagar, D., Soran, H., Durrington, PN. 2008. Hypercholesterolaemia and its management. BMJ, 337, a993.

[2] Mannu, GS., Zaman, MJ., Gupta, A., Rehman, HU., Myint, PK. 2013. Evidence of lifestyle modification in the management of hypercholesterolemia. Curr Cardiol Rev, 9, 2-14.

[3] Swiger, KJ., Manalac, RJ., Blumenthal, RS., Blaha, MJ., Martin, SS. 2013. Statins and cognition: a systematic review and meta-analysis of short-and long-term cognitive effects. Mayo Clin Proc, 88, 1213-21.

[4] Abd, TT., Jacobson, TA. 2011. Statin-induced myopathy: a review and update. Expert Opin Drug Saf, 10, 373-87.

[5] King, D., Mitchell, B., Williams, CP., Spurling, GK. 2015. Saline nasal irrigation for acute upper respiratory tract infections (PDF). Cochrane Database Syst Rev, CD006821.

[6] Hao, Q., Dong, BR., Wu, T. 2015. Probiotics for preventing acute upper respiratory tract infections. Cochrane Database Syst Rev, 9, CD006895.

[7] Viswanathan, VK., Hodges, K., Hecht, G. 2009. Enteric infection meets intestinal function: how bacterial pathogens cause diarrhoea. Nat Rev Microbiol, 7, 110-9.

[8] Avellaneda, Fernández. A., Pérez, Martín A., Izquierdo, Martínez. M., et al. 2009. Chronic fatigue syndrome: aetiology, diagnosis and treatment. BMC Psychiatry, 9 (Suppl 1), S1.

[9] Simons, KJ., Simons, FE. 2010. Epinephrine and its use in anaphylaxis: current issues. Curr Opin Allergy Clin Immunol, 10, 354-61.

[10] Bilò MB. 2011. Anaphylaxis caused by Hymenoptera stings: from epidemiology to treatment. Allergy, 66 Suppl 95, 35-7.

[11] Warren, JD., Blumbergs, PC., Thompson, PD. 2002. Rhabdomyolysis: a review. Muscle Nerve, 25, 332-47.

[12] Gartner, LM., Morton, J., Lawrence, RA., Naylor, AJ., et al. 2005. Breastfeeding and the use of human milk. Pediatrics, 115, 496-506.

[13] Kajinami, K., Takekoshi, N., Saito, Y. 2003. Pitavastatin: efficacy and safety profiles of a novel synthetic HMG-CoA reductase inhibitor. Cardiovasc Drug Rev, 21, 199-215.

[14] Song, BL., Sever, N., DeBose-Boyd, RA. 2005. Gp78, a membrane-anchored ubiquitin ligase, associates with Insig-1 and couples sterol-regulated ubiquitination to degradation of HMG CoA reductase. Mol Cell, 19, 829-40. 
[15] Miziorko, H. 2011. Enzymes of the mevalonate pathway of isoprenoid biosynthesis. Arch Biochem Biophys, 505, 131-143

[16] Sulzer, NU., Schwellnus, MP., Noakes, TD. 2005. Serum electrolytes in Ironman triathletes with exercise-associated muscle cramping. Med Sci Sports Exerc, 37, 1081-5.

[17] Mukhtar, RY., Reid, J., Reckless, JP. 2005. Pitavastatin. International Journal of Clinical Practice, 59, 239-52.

[18] Kawashiri, MA., Nohara, A., Tada, H., et al. 2008. Comparison of effects of pitavastatin and atorvastatin on plasma coenzyme Q10 in heterozygous familial hypercholesterolemia: results from a crossover study. Clin Pharmacol Ther, 83, 731-9.

[19] Vecchio, Ignazio., Tornali, Cristina., et al. 2018. The Discovery of Insulin: An Important Milestone in the History of Medicine. Front Endocrinol, 9, 613.

[20] Hill, NR., Levy, JC., Matthews, DR. 2013. Expansion of the homeostasis model assessment of $\beta$-cell function and insulin resistance to enable clinical trial outcome modeling through the interactive adjustment of physiology and treatment effects: iHOMA2. Diabetes Care, 36, 2324-30.

[21] Gois, Pedro Henrique França., Souza, Edison Regio de Moraes. 2020. Pharmacotherapy for hyperuricaemia in hypertensive patients. Cochrane Database Syst Rev, 9, CD008652.

[22] Heinig, M., Johnson, R J. 2006. Role of uric acid in hypertension, renal disease, and metabolic syndrome. Cleve Clin J Med, 73, 1059-64. 